Case Report

\title{
Nonfamilial Juvenile Polyposis Syndrome with Exon 5 Novel Mutation in SMAD 4 Gene
}

\author{
Amna Ahmed and Badr Alsaleem \\ Pediatric Gastroenterology and Hepatology Division, Children's Hospital, King Fahad Medical City, Riyadh, Saudi Arabia \\ Correspondence should be addressed to Amna Ahmed; amnabasheer13@yahoo.com
}

Received 17 October 2016; Accepted 2 March 2017; Published 27 March 2017

Academic Editor: Ozgur Cogulu

Copyright (C) 2017 Amna Ahmed and Badr Alsaleem. This is an open access article distributed under the Creative Commons Attribution License, which permits unrestricted use, distribution, and reproduction in any medium, provided the original work is properly cited.

\begin{abstract}
Juvenile polyposis syndrome (JPS) is a rare autosomal dominant hereditary disorder, characterized by multiple juvenile polyps in the gastrointestinal tract and an increased risk of colorectal cancer. JPS is most frequently caused by mutations in the SMAD4 or BMPR1A genes. Herein, we report a child with juvenile polyposis syndrome (JPS) with a novel mutation in the SMAD4 gene. An 8 -year-old boy presented with recurrent rectal bleeding and was found to have multiple polyps in the entire colon. The histology of the resected polyps was consistent with juvenile polyps. Subsequent genetic screening revealed a novel mutation in SMAD4, exon 5 (p.Ser144Stop). To the best of our knowledge, this mutation has not been reported before. Offering genotypic diagnosis for patients with JPS is an important step for strategic plan of management.
\end{abstract}

\section{Introduction}

Juvenile polyposis syndrome (JPS) is a rare autosomal dominant hereditary disorder with an estimated incidence of 1 in $100,000-160,000$ individuals. It is characterized by multiple distinct juvenile polyps in the gastrointestinal tract and an increased risk of colorectal cancer [1]. This disorder is most frequently caused by mutations in the SMAD4 or BMPR1A genes, but together these genes accounts for only $40 \%$ of cases [2].

\section{Case Report}

An 8-year-old Saudi boy presented to the Gastroenterology service, with a 3-year history of recurrent rectal bleeding, generalized abdominal pain, loose motions, and fatigability. The patient is product of a consanguineous marriage and family history is unremarkable for gastrointestinal (GI) bleeding or GI malignancies. Apart from pallor, physical examination was unremarkable. Initial laboratory work up showed features of iron deficiency anemia. Esophagogastroduodenoscopy (EGD) was unremarkable. However, colonoscopy revealed dozens of pedunculated and sessile polyps of different sizes (range of $10-30 \mathrm{~mm}$ ), distributed along the entire length of the colon (Figure 1). The histological analysis of the polyps showed hamartomatous features that were consistent with juvenile polyposis (Figure 2). Video capsule endoscopy (VCE) excluded small intestinal involvement (Figure 3). The diagnosis of JPS was made, based on endoscopic and clinicopathological findings. After obtaining a written and informed consent, genetic test was done, detecting a previously nonreported, heterozygous mutation in SMAD4: sequence defined as c. $431 \mathrm{C}>\mathrm{G}$ and predicted to result in premature protein termination (p.Ser144Stop), in exon 5. However, the patient's biological members genetic screening was unremarkable.

Attempts for endoscopic colonic polyp clearance were made, but this had been unsuccessful due to large polyps burden. Given the worsening of gastrointestinal bleeding and iron deficiency anemia and avoiding other complications such as intussusception and colorectal cancer, total colectomy was done. Long term follow-up was planned by conducting surveillance with upper endoscopy every 1 to 2 years and small bowel evaluation every 2 to 3 years. 

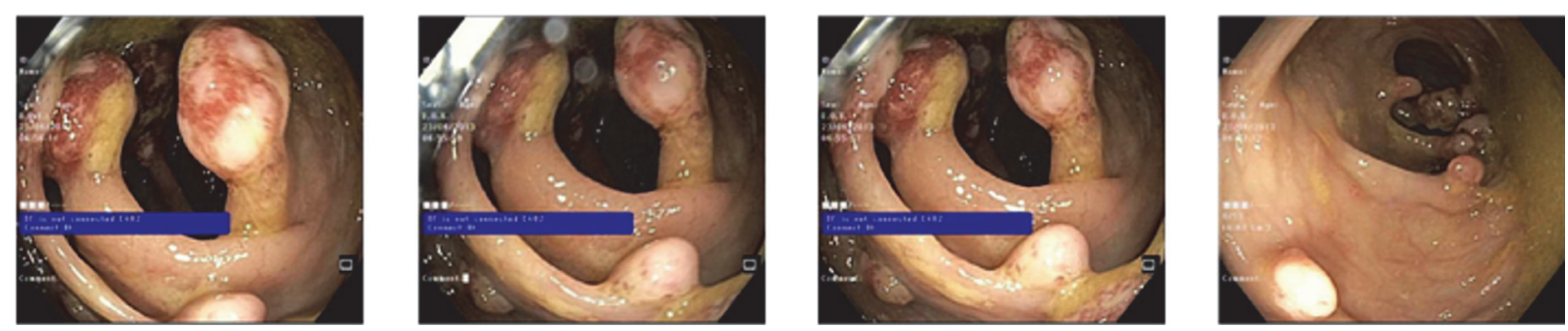

FIGURE 1: Multiple pedunculated and sessile, nonbleeding polyps were found in the entire colon more and larger in the right colon. They are $>80$ in number with variable sizes (ranging from few millimeter to $3 \mathrm{~cm}$ ).

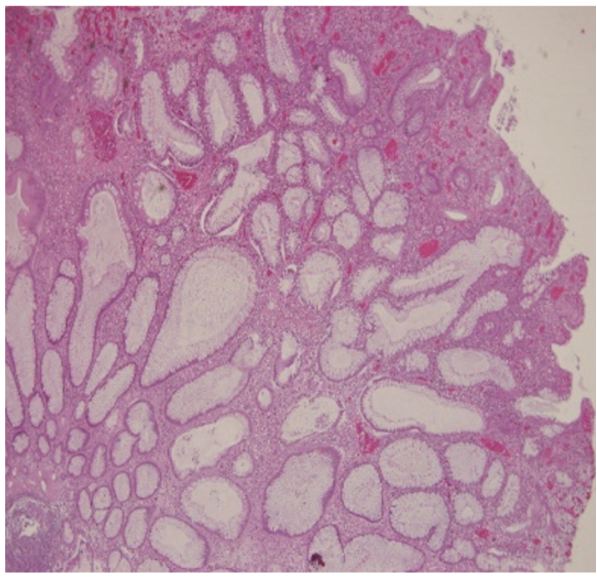

(a)

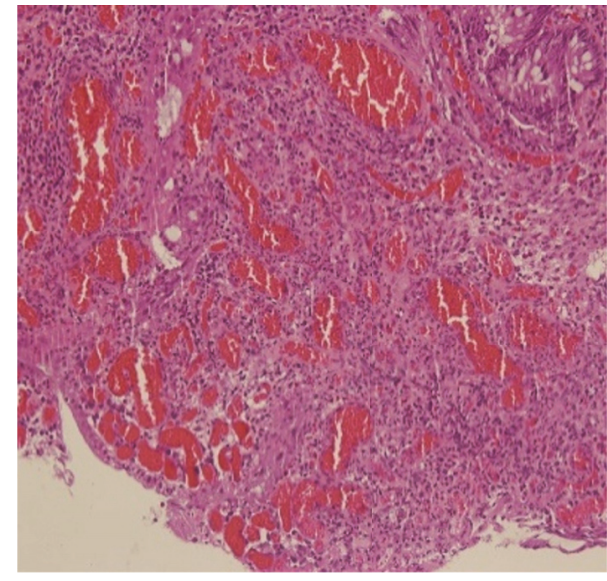

(b)

FIGURE 2: Edematous lamina propria, cystically dilated glands (a) with inflammatory cells (b) in resected tissue obtained from colonoscopic polypectomy (H\&E stain, $\times 40)$.

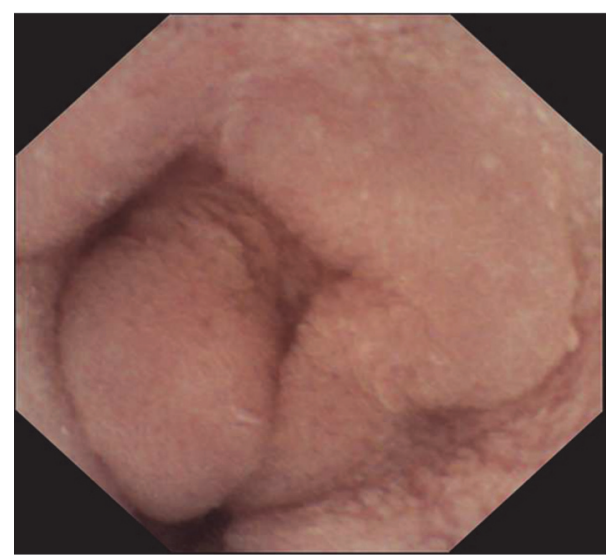

FIGURE 3: Video capsule endoscopy (VCE): One image from small intestine: No polyps seen.

\section{Discussion}

The case describes an 8-year-old male, proved to have JPS, and the genetic study detected a nonfamilial, novel spontaneous mutation in SMAD4 in exon 5.

Approximately, $20-50 \%$ of patients with PJS have a family history, while about $25-50 \%$ of patients have new mutations [3].
The most common mutation in SMAD4 is a 4-base deletion at exon 9 [4]. Other reported novel gene mutation in SMAD4 was found in exon 10, in a family with familial juvenile polyposis syndrome (FJP) [5].

Common presenting symptoms of JPS include rectal bleeding, anemia, abdominal pain, and less commonly rectal prolapse of polyps [6].

If JPS diagnosis is made, the entire gastrointestinal tract should be examined endoscopically or radiologically for detecting polyps. Video capsule (VCE) is one of modalities used for polyps detection [7]. In our case VCE was done (preceded by abdominal computerized tomography scan) and it was unremarkable for small intestinal polyps. Macroscopically, juvenile polyps vary in size from 5 to $50 \mathrm{~mm}$, typically having a spherical, lobulated, and pedunculated appearance, with surface erosion. Microscopic features include edematous lamina propria with inflammatory cells and cystically dilated glands [1].

SMAD4 gene mutations predispose to a more aggressive gastrointestinal phenotype with increased risk for gastric and colorectal cancer, compared to other mutations such as the BMPR1A. Patients with JPS should be subjected to yearly endoscopic clearance until they are deemed polyp-free [8]. Thus, genotypic diagnosis for children affected by JPS is an important step in the management. Once the gene mutation is identified, screening for at risk family members will be 
planned for and the future surveillance strategic plan for the gene carriers will be determined.

Prophylactic colectomy should be considered in those with large colonic polyps burden in whom endoscopic clearance is not possible, in patients with severe gastrointestinal bleeding or diarrhea, and, lastly, if there is a strong family history of colorectal cancer [9]. Hence, prophylactic total colectomy was done for our patient.

\section{Conclusions}

To the best of our knowledge, this SMAD 4 gene mutation, in patients with JPS, was not described before.

Offering genotypic diagnosis for patients affected by JPS is an important step in the strategic plan of management.

\section{Conflicts of Interest}

The authors declare that they have no conflicts of interest.

\section{References}

[1] L. A. A. Brosens, D. Langeveld, W. A. van Hattem, F. M. Giardiello, and G. J. A. Offerhaus, "Juvenile polyposis syndrome," World Journal of Gastroenterology, vol. 17, no. 44, pp. 48394844, 2011.

[2] J. F. Rafferty, "Polyps and polyposis coli," Clinics in Colon and Rectal Surgery, vol. 21, no. 4, pp. 235-236, 2008.

[3] M. P. Bronner, "Gastrointestinal inherited polyposis syndromes," Modern Pathology, vol. 16, no. 4, pp. 359-365, 2003.

[4] T.-T. Wu, B. Rezai, A. Rashid et al., "Genetic alterations and epithelial dysplasia in juvenile polyposis syndrome and sporadic juvenile polyps," American Journal of Pathology, vol. 150, no. 3, pp. 939-947, 1997.

[5] M. J. Jee, S. M. Yoon, E. J. Kim et al., "A novel germline mutation in exon 10 of the SMAD4 gene in a familial juvenile polyposis," Gut and Liver, vol. 7, no. 6, pp. 747-751, 2013.

[6] I. R. Schreibman, M. Baker, C. Amos, and T. J. McGarrity, “The hamartomatous polyposis syndromes: a clinical and molecular review," American Journal of Gastroenterology, vol. 100, no. 2, pp. 476-490, 2005.

[7] E. Chow and F. Macrae, "Review of juvenile polyposis syndrome," Journal of Gastroenterology and Hepatology, vol. 20, no. 11, pp. 1634-1640, 2005.

[8] J. R. Howe, J. C. Ringold, J. H. Hughes, and R. W. Summers, "Direct genetic testing for Smad4 mutations in patients at risk for juvenile polyposis," Surgery, vol. 126, no. 2, pp. 162-170, 1999.

[9] P. Moguelet, L.-F. Plassa, J. Métayer et al., "SMAD4-related familial juvenile polyposis syndrome with colon cancer," Cancer Genomics and Proteomics, vol. 1, no. 1, pp. 33-38, 2004. 


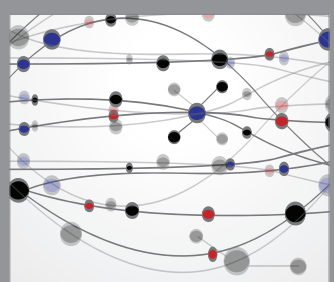

The Scientific World Journal
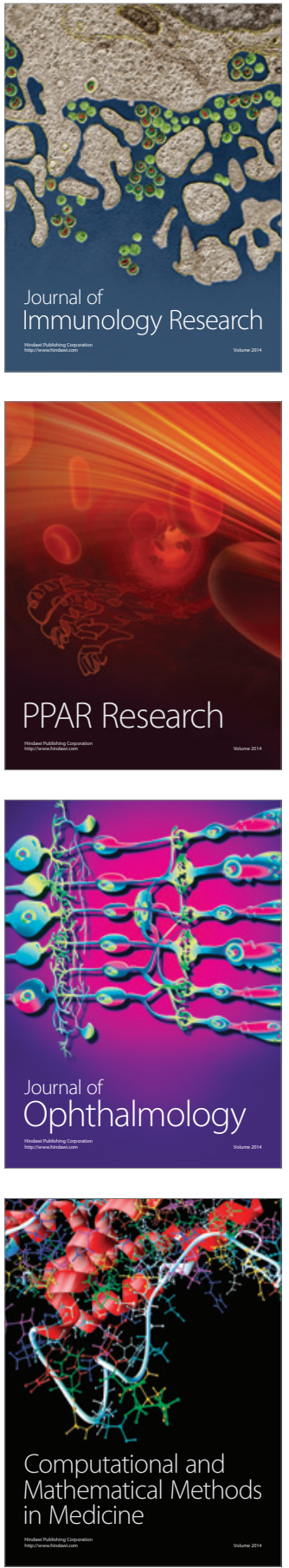

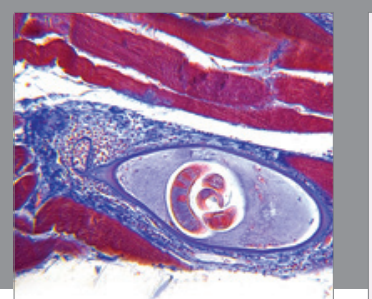

Gastroenterology Research and Practice
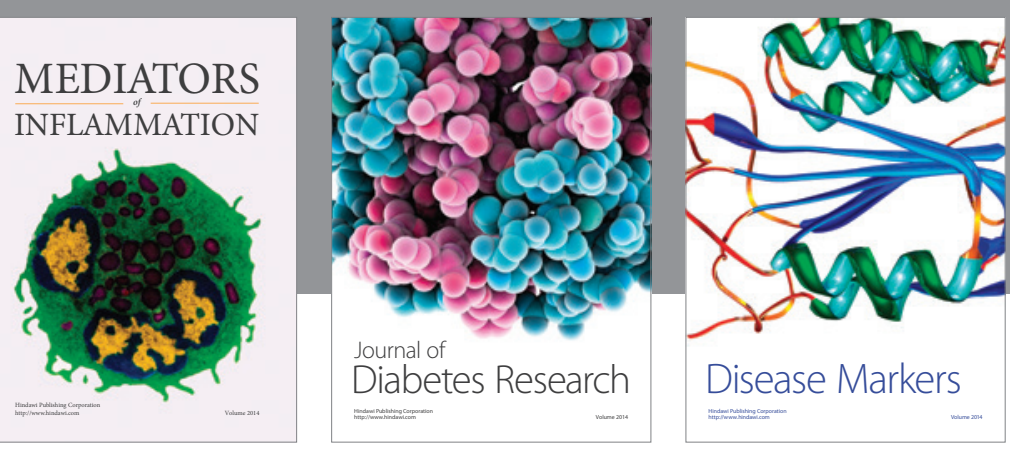

Disease Markers

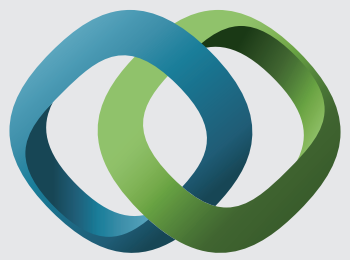

\section{Hindawi}

Submit your manuscripts at

https://www.hindawi.com
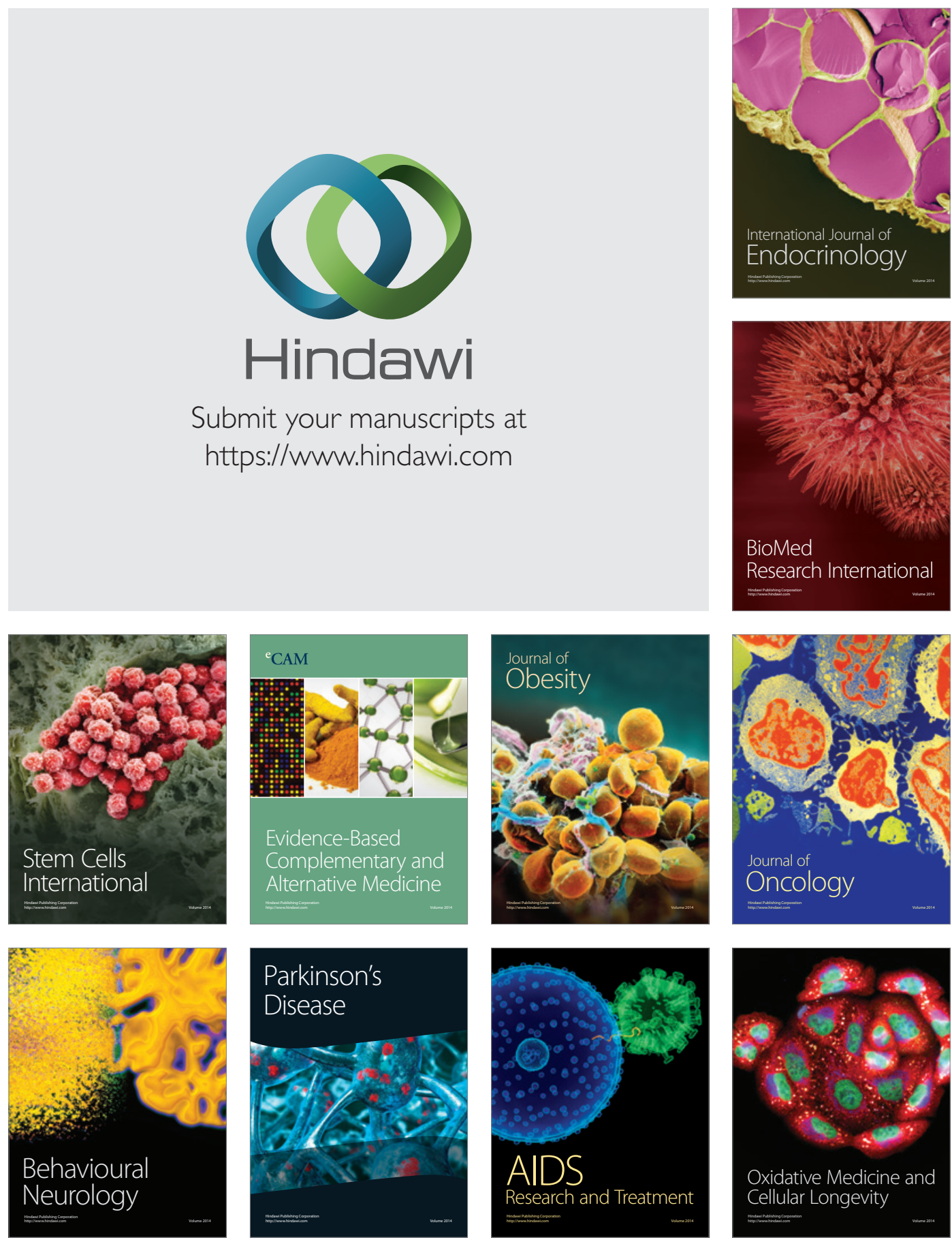